\title{
Psychopaths are not that "successful"
}

\author{
Pardis Tabaee Damavandi
}

\section{Dear Editor,}

I read the article on "Corporate psychopaths in public agencies"[1] and although I am in agreement with it, I would like to propose alternative views on the "subjects" exerting destructive behaviours violating the legitimate interests of an organisation.

Firstly the pathology of the socio-economic imbalance which leads to a raise in psychopathy across the population is due to recreational substance consumption. All discriminatory (anti-social) acts co-exist with the "diagnosis" of dangerous psychopathy which always is in synchronicity with substance abuse issues. As we know psychopathy is not a recognised disease and is not a mental illness. It would be a risk for society to treat it as such; this radical interpretation was debated in the 19th century by sociologists such as Durkheim, either by supporting the perspectives of psychopaths, who claimed crime is the only way to live, or contrasted by contemporary sociology and psychology. ${ }^{[2]}$

Modern sociologists however do believe that even "criminals" must abide by the law. In that sense, "criminal" assumes a broad definition in which there are unfortunately innocents convicted of crimes "waiting" on justice, hence are not "criminals", whilst there exist true criminals that can also be those who convict innocents of crime (as in the case of organised criminal groups that access police and lead to the so-called false imprisonment, or "kidnapping"). The latter are particularly common in mixed law countries, less common and still present, within common law jurisdictions and rare in civil law systems. In those societies it is a public authority figure that is said to be the provider of crime through "smaller organizations". Within that situation, the "corruption" is both biological and moral. Normally the psychopath working for the small criminal organisation justifies legalisation of for example certain drugs biologically, as medicine decisively contrasts those "ignorant" views. Likewise, the pharmacist who provides controlled drugs without a prescription is doing so not just immorally, but also against the rules set by pharmacology, and her or his competence or knowledge become questionable. This is unlikely to happen thanks to modern formative and training methods 
offered by "top" Universities. Drugs are thus misused because of a matter of competence, and ignorance, since not everyone is aware of what authority really entails. ${ }^{[3]}$

The belief that police is authority and not the State is widespread in certain areas of the world, whereas the only role of law enforcement is that of maintaining order under the rule of law and under authority. Often that belief is spread by the "unreal" police as above-mentioned, thus by the criminal or "successful" psychopaths and by their "supporters" which can sometimes extend to entire companies or corporations. This is possible in mixed law systems because in those contexts there is no segregation, no dissent and no opposition, in short, there is no actual democracy. The misconduct officer is a clear example of "successful psychopath", only he or she is not that successful, simply has not yet been "detected" for the reasons explained previously. The famous psychologist Hare made a list reporting all sorts of many other "exemplary professionals". ${ }^{[4]}$

An account on psychopaths is also provided by sociologists Petrażycki and Hägerström as translated by Italian sociologist Fittipaldi in which he explains that, the psychopath is born to harm and "its" only life-objective is that of inflicting pain. ${ }^{[5]}$ In synthesis, the psychopath cannot think of anything else other than to harm others. Morality across that population is absent, partially or completely, depending on the gravity of the condition and on how long the psychopath has been undetected for.

\section{On the analysis of subjects mentioned}

That being said, the article establishes that corporate psychopaths often find themselves in managerial positions. It is possible for psychopaths to end up being in managerial positions however it is not that frequent. Their climbing the ladder is simply quicker than the honest individual's, but more often than not psychopaths are found in the "middle". The psychopath could be a call handler at any company, a secretary or administrative assistant, a recruiter and so on. The infiltration inside each profession is thus favoured by the "psychopath established in the middle". In that sense Lenin states that "bourgeoisie is very weak", morally speaking, that is referred to ancient feudal hierarchies. So perhaps Lenin had already identified that the problem was also in the middle, not simply "in authority". Along the same lines is Marx who previously explains that the middle class is repeating the same mistakes the aristocratic class had made prior to the industrial revolution. Yet, democracy is about a class in the form of a party dominating the capital over another class therefore the principle of democracy is admirable to 
him but utopian, even though Marx demonstrates hope in democracy itself, possibly due to the presence of conflict itself and of opposition which reminds us of ancient societies where intellectuals used to openly express diverging opinions in order to find a solution to a specific social problem.

Hägerström, on the other hand, views psychopaths as those who choose to act immorally, in disagreement with Petrażycki who felt that the psychopathic population does not care about anything but to harm and cannot think of anything else.

\section{Psychopathy is contagious}

The risk of psychopaths being recruited in public administration or agencies is frightening and it is becoming contagious ${ }^{[6]}$, but it is a bottom up event instead of a top down one. With that I mean that it is much harder for an intellectual to hire a non-intellectual, thus the psychopath acts via pre-established criminal or vulnerable hooks and "infiltrates", as studied previously. Hare states that the "cunning" attitude is what tricks others into them getting hired; as we know, other experts have claimed that psychopaths ask and offer favours, to get hired. The number of psychopathic recruits increases dissatisfaction and decreases happiness across society as a whole. The psychopath is by definition a coward and "hides", the more "it" hides the less the victims know about the psychopath, the better "it", immoral subject, can carry out his or her activities. Victims are not aware of the psychopath's activities until after a violation of the victim's rights has occurred. Either the denial of the psychopath (which is questionable as evidence cannot be denied) are source of their acceptance within society, or, the psychopath's untruthful motives lead to a vicious cycle of violations until the impact of the psychopath on society is so drastic that other honest persons are unconsciously or unknowingly "converted" into one themselves. Then the psychopath will hold those same actions they pushed the former honest person to perform, against them in exchange of more favours (sometimes beyond legal limits, but surely immoral) or else there will be recrimination. That "epidemic spread" can only be prevented by detecting it and exposing it.

Psychopathy is also contagious. Not always this is the case, in a majority of situations, i.e. with women victims of violence, it is nearly impossible for the psychopath to obtain any such favours by the victim, leading the psychopath to retaliatory behaviour. Victims of violence are often clear on their boundaries and morals and psychopaths dislike boundaries. Nonetheless, the root problem to psychopathy and its increase is, as Vaknin states, its contagious aspect. Criminal 
organisations can also become transnationally supported exacerbating this "pathological symptom" (and not disease). ${ }^{[7]}$

\section{Incompetence and psychopathy}

Incompetence sustains psychopathy in the way that the more incompetent a person is the more likely it is going to be for an individual in turning into a subject of committing certain actions, due to a diminished intelligence. The hypothesis that psychopaths are less intelligent by the rest of the population is very probable and proven by their lack of problem solving skills, however it is also true that all they can do is cause problems, but if we viewed causing harm as a measure of "making something worse" rather than "creating discomfort" in other people's lives as a ways of exerting control over others, then it is certain that the lack of intelligence is a probable cause. Likewise, if we viewed deception as an inability to demonstrate analytical observation, then it is again easy to correlate it with a lack of intelligence, rather than associating it inability to a skill, such as "charisma" or in an ability to "influence others" which had been proposed by former articles.

As a matter of fact, a psychopath just refuses to learn, therefore a solution is, during the recruitment process, to demonstrate that the individual is willing to learn, isn't competitive with or exploitative of others when reaches a certain "rank", thus doesn't misuse its office to form "alliances", to expand its unprofessional (not required by the profession) activities, and that the subject who wants to be a part of said company has problem solving skills. It is obvious that the lack of problem solving skills, which is simply based on the "desire" of solving problems and the desire to do so automatically will lead to the learning process and better worker performance for the company. Relationships between worker and manager need to be present, as Engels states, in order for performance to be assessed appropriately, not through micromanaging but through profound questioning in the early stages of recruitment; since psychopaths are willing to lie, of course they are by definition dishonest.

These almost "functional" views, are not excluding psychopaths from society. It is the same criterion applied to all the population and based on constitutional laws, which is why even psychopaths need to follow and accept laws. Psychopaths have in principio, the same rights and opportunities as non-psychopaths, but they want privileges whilst denying others any rights, irrationally.

\section{A lack of empathy is exclusive to psychopaths}


Fundamental animal rights have been recently introduced due to the shown ability of even animals in feeling empathy. The psychopath remains the only living organism unable to feel any. The psychopath has been mistakenly associated with animal predators. The difference is that even animals, carnivores included, are capable of feeling empathy. This is supported by "choking deaths" on live preys by carnivores which goes against self-preservation instincts (detected instead in psychopaths who have a propensity to egocentrism). In the animal it is a biological involuntary instinct, a bit like the bundle of his provoking disconnected by our "brain" and similar to a reflex. The psychopath's actions are, instead, often voluntary and their reflexes are reduced due to substance consumption. Biological memory in animals works in allowing them the ability to provide for themselves which is unlike the psychopath's severe inabilities and in mixed law systems those inabilities are overlooked by its similars.

The psychopath, on the contrary, has poor impulse control and has zero self-control. The only ability of the psychopath is by means of exploiting society. The psychopath is unable of progress, improvement and growth unless granted to him or to her by third parties and society itself, no matter how secretly it despises it. A psychopath is never excluded by society, it needs it. The State doesn't exclude anyone, after all.

Predatory animals are self-sufficient and are excluded and hunt for themselves, but above all, are capable of feeling empathy. For example, both the polar bear, world's strongest predator and cat (a domestic carnivore) have shown highly intelligent, empathetic behaviours through, for example, adoption. Armstrup adds that even polar bears can become domestic animals without a need for captivity. ${ }^{[8]}$

One way to resist psychopaths is by not giving into their demands and this can only be achieved with morals. Morals are a given, through the simple tool of knowledge. A simple test can help us assess who we are dealing with and what we can refuse, sometimes it even provides us with instruments in how to deal with whoever we are dealing with. Another way to "unmask" a psychopath is to shut out our emotions, through the rejection of our optimism, or of our pro-social and dependency instincts, which hinder our proper perceptions. Logic is a psychopath's worst enemy. Lastly, independence or a love for freedom as well as for justice, is morality's best companion. When we are aware that substances can induce us into certain harmful or unhealthy patterns, we can refuse them, even though coercion was in place or 
emotions were involved, because we logically measure the type of damage rather than choosing emotion.

Nevertheless, the fairest the society and public administration are towards the citizens the least likely it is for citizens to commit crimes as PA will protect us from psychopaths rather than supporting them (common in mixed law systems). ${ }^{[9]}$

\section{NO CONFLICTS OF INTEREST TO DISCLOSE}

\section{References}

1. Hanson L, and Baker D. L., Corporate Psychopaths in public agencies, J. Of Public Manag. And Soci., 2017, (Spring 2017): 21-41.

2. Baehr, P. "The 'Iron Cage' and the 'Shell as Hard as Steel': Parsons, Weber, and the Stahlhartes Gehäuse Metaphor in the Protestant Ethic and the Spirit of Capitalism." History and Theory, JSTOR, 2001, 40(2), pp. 153-69 www.jstor.org/stable/2678029.

3. Ricciardi M., Rossetti A., Velluzzi V., Filosofia del diritto. Norme, concetti, argomenti, Chapter 3, Carocci ed., 2019, Rome, Italy.

4. Babiak P., Hare R. D., "Snakes in Suits: When Psychopaths Go to Work". Psychology Today. 39 (5): 36. September 2006.

5. Fittipaldi E., Everyday Legal Ontology: A Linguistic and Psychological Investigation within the Framework of Leon Petrażycki's Theory of Law. Milan, 2012.

6. Vaknin S., Malignant self love, Project Gutenberg Consortia Center., 2003

7. Bellucci L., I reati culturalmente motivati tra conflitti normativi e dimensione geopolitica: l'escissione come crime nella giurisprudenza francese, Questione giustizia, 2017, (Fascicolo 1/2017):1.

8. Amstrup, S. C., 2003. Polar bear, Ursus maritimus. Chapter 27 In Wild mammals of North America: biology, management, and conservation. Edited by G.A. Feldhamer, B.C. Thompson, and J.A. Chapman. John Hopkins University Press, Baltimore. pp. 587-610.

9. Moore S. F., " Certainties undone : fifty turbulent years of legal anthropology, 1949-1999* "The Journal of the Royal Anthropological Institute 7 (2001) : 95-116. 


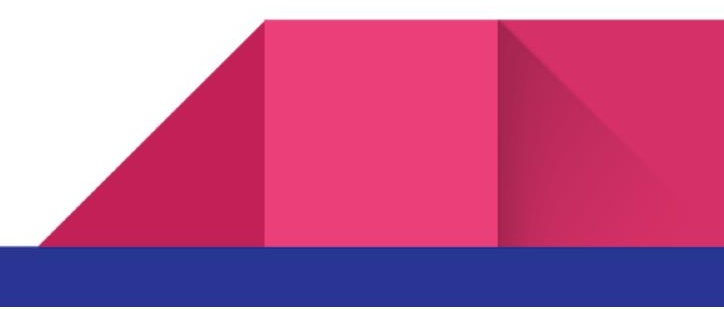

